\title{
Empirical Research on Factors Influencing Students' Decision to Study Abroad using Cart Analysis
}

Adriana DIMA ${ }^{1}$

Abstract
The main objective of this paper is to identify the main factors that determine
students to continue their studies abroad or in their home country. A quantitative
research is conducted through a questionnaire applied on a representative sample of
students from The Bucharest University of Economic Studies. Data analysis is
performed using SPSS and CART. The results indicate that the primary reasons
students opt to continue their studies abroad is to achieve better quality education and
social status. Furthermore, the parents' level of education influences the students to
continue their studies in the home country. The conclusions of the study suggest that
students whose parents have a high level of education are more confident about their
chances of success in their home country and consider that they can benefit from a
quality education even without leaving abroad. Moreover, students whose parents have
less than a high school diploma wish to overcome their condition and to obtain a
significant social prestige due to the studies undertaken abroad.

Keywords: internationalization, study abroad programs, international students, CART methodology.

JEL classification: F22, I21, I25, O15.

DOI: $10.24818 /$ RMCI.2019.4.449

\section{Introduction}

Due to the expansion of globalization, nowadays, universities are no longer able to operate in a limited space. Regionalization and globalization processes imply higher education to generate a new education system that would subsequently become a major leap in the national and continental economy's creative growth.

Taking into consideration this arising issue, it is stringent the need to reinvigorate study programs as well as the university curriculum overall, to launch new fields of study and disciplines, and to attract and maintain international students enrolled in university programs. Without such improvements, a competitive higher education cannot be created.

International education has become a competitive industry for several decades, with a dramatic increase in the number of students who choose to study abroad. Growth in tertiary education internationalization represents economies and

\footnotetext{
${ }^{1}$ Adriana Dima, Bucharest University of Economic Studies, e-mail: Adriana.dima@ man.ase.ro
} 
societies globalization, as well as the growth of tertiary systems and institutions worldwide.

Foreign students constitute an important asset for the host nation's society and culture. In addition, they contribute significantly to the development of research and innovation in the receiving country. Therefore, student mobility through strategic partnerships becomes increasingly important for both universities and countries (Beine, Noël \& Ragot, 2014).

The higher education system is an essential component in the development of young individuals and society by generating and improving awareness, transmitting it to students and promoting creativity (Schnickel, Martin, \& Maruyama, 2010). There are many benefits of pursuing a study program at a university abroad. The architecture of the education system, the curricula and initiatives reflecting the labour market dynamics, the innovations, the international research climate, an international career which could be developed during the studies and the prospects for advancement in an environment that relies on the abilities of the individual and preoccupations of the undergraduates are just a few of them.

It is vital to understand what factors determine the decisions of international students to study abroad in order to be able to attract more international students. Many regions like the U.S., Canada and Australia attract international students who, in return, are stimulating the economy with vast amounts of money and generating a substantial amount of work for the host country. While international students not only pay tuition fees, they also spend a considerable amount on housing, bills, etc. (Mazzarol \& Soutar, 2002). In states such as the United Kingdom, the United States of America, Germany, France or in the Netherlands, academic institutions have welltrained, empowered and qualified professors in the field, providing modern amenities and resources, and perhaps the most important, undertaking permanent efforts to improve the learning system and the opportunities provided to students. Such continuous efforts were illustrated on various quantifiable indicators in the global university graphs. International program studies as well as associated diplomas offer graduates easy access to better prospects on a global labour market.

In addition, numerous study programs are designed to facilitate students to acquire skills that can be quickly put into practice, thus, substantially shortening the time needed for graduates to adapt to their first job. Students from abroad universities benefit from a competitive advantage when searching for a future job, completed in a foreign degree, as well as a possible internship in the area that was studied.

In the context of an intensive international competition to attract foreign students around the world, it is mandatory to fully understand the influencing factors for students to choose a particular study destination. Nevertheless, limited research has concentrated on factors that play an important part in the intention of foreign students to opt for a certain study destination. To tackle this, the current study aims to fill the research void in order to identify the personal factors that influence the decision of Romanian students to continue their studies abroad. 


\section{Literature review}

The globalization process has changed the world's economic, political, and cultural structures, enhancing the emphasis of the higher education internationalization strategy and the significance of human capital for countries' competitiveness. Recognizing higher education diplomas at national, regional and global level is a significant issue in this regard.

The global economic crisis has driven the introduction of new perspectives on the dimensions and approaches of globalization in the context of internationalization of higher education. Therefore, in several highly industrialized countries like China, South Korea, Japan and others, alongside the economic advancement, there are revolutionary developments in the quality of new technologies at these countries' universities. Prior information technologies have become obsolete, and higher education must implement more pronounced impulses to boost the domestic, continental and global economic momentum in order to upgrade modern, more competitive ways.

In the sense of a globalizing world, studying abroad is often seen as one of the main resources for providing foreign language skills and intercultural skills to undergraduate students in order to improve their employability (Parey \& Waldinger, 2010; Van Mol, 2014). Multi-national companies in particular consider the value of studying abroad experience (Kratz \& Netz, 2018; Petzold \& Moog, 2018). In addition, positive effects on learning skills and linguistic abilities (Luo \& Jamieson-Drake, 2015) and intercultural openness and personality growth (Zimmermann \& Neyer, 2013). Studies abroad are often seen as one of the main resources for providing language skills and intercultural skills to students (Parey \& Waldinger, 2010).

For several factors, developing countries are particularly interested in attracting international students. Firstly, international students are a substantial source of income for universities, as foreign students usually pay higher fees compared to domestic students in many countries (Beine, Noël \& Ragot, 2014). Secondly, higher education offered to international students represents a powerful tool for the diffusion of social, economic and political values in host countries (Spilimbergo, 2009). Thirdly, students ' international mobility is highly associated with a different type of migration, that of professional and highly skilled employees (Docquier \& Rapoport, 2012).

Internationalization takes on different dimensions under the influences of globalization that open up multiple interesting opportunities for institutions and structures of higher education. Likewise, real risks and threats are intrinsic in such a volatile environment, therefore competitiveness challenges and international significance require special initiatives and strategic thinking for all types of higher education. Globalization and internationalization have exerted on universities various facets of motivation to attract foreign students. For some states, high economic returns are achieved by educational exports. In Australia, for example, higher education is the third largest export industry in the world (Koshy \& Phillimore, 2013). More than $\$ 18.6$ billion was generated by international students in 2010. Because of a growing trade deficit, universities were given $\$ 200,000$ by the Australian government to print 
promotional materials that would draw foreign students. Universities are allowed to retain most of the income of international students as a measure of economic support (Brandenburg \& De Wit).

Certain essential points, except the economic standpoint, are the promotion of culture and interaction (Anderson \& Lawton, 2015). For instance, fiscal austerity does not affect public institutions of higher learning in Hong Kong, thus income is not the main motivator. The recruitment of students at universities in Hong Kong indicates the advancement of social culture and the preservation of the international reputation of Hong Kong (Bodycott, 2009). Students from different backgrounds and regions in Hong Kong are able to expand their knowledge of China and play a constructive role in promoting the ethnic understanding and tolerance of students. Economies such as Singapore see the recruitment of international students as a way to increase and sustain the competitiveness of fields of study such as science, technology and economy (Bodycott, 2009). They also collaborate with other world-renowned universities by introducing the global strategy to increase the brand image and help improve the position in the world rankings (Sidhu, Ho \& Yeoh, 2014).

Universities in Sweden emphasize the importance of the experience of international students and the international influence of education and research. Thus, student mobility has become more and more relevant through strategic partnerships. International graduate students have a competitive advantage over other candidates for a future job, completed with a foreign degree, and also a possible internship in the sector under research (Ahmad, Buchanan \& Ahmad, 2016). Most universities provide internships to attract new staff in partner companies (Netz, 2015). International program studies and associated diplomas offer easy access to the best prospects on a global labour market. In addition, many of the study programs are structured to help students acquire new skills which could be put into effect effectively, greatly shortening the time needed to adapt to the first workplace (Petzold \& Moog, 2018). In summary, at that point, career earnings surpass the time needed to fulfil the studies.

The period of time spent learning and researching in another countries significantly expand each individual's personal and professional horizons (Lewis, 2016). Students will communicate with peers from cultures that are completely different from theirs and draw positively values that form their future.

\section{Research Objectives and Methodology}

The main objectives of this study are to research the influencing factors of Romanian students to study abroad and to provide suggestions for higher institutions in the country to attract more international students.

The empirical research is constructed on three hypotheses $(\mathrm{H})$ to determine correlations between several main variables as follows:

H1. There is a significant correlation between the parents' level of education and the student's intention to study abroad;

H2. Students who have travelled to other countries prefer to study abroad; 
H3. The primary reason why students intend to study abroad is to benefit from better quality training.

To examine the determinants of the student's decision to study in another state, qualitative research is conducted using a questionnaire applied to a representative student sample from Bucharest University of Economic Studies, Romania. The questionnaire items were tailored to a Romanian study and the questionnaire was distributed to a sample containing both undergraduate students enrolled in the English language program and in the Romanian language program in an approximately equal proportion. The selected questions were closed, namely the answers were predetermined, and the respondents had to select one or more answers from the proposed ones. The questions were of several types: with a single response, with several responses or with scales of attitudes from 1 to 5. Data collected is analysed by using SPSS.

CART has been used to statistically demonstrate the variables of explanatory power and variation that are particularly important in determining students to study abroad. CART provides a sophisticated image of the data relationship of variables and can be used as a first phase in the creation of an informative model or a final visualization of essential associations (Morgan, 2014). CART does not take on a particular form of relationship between independent and dependent variables. CART aims at constructing a decision tree predicting the characteristics of the sample being studied.

\section{Research findings}

There were included five independent variables: (I) What is your parent's highest level of education?, (II) Initial home environment, (III) Have you travelled to another country?, (IV) Have you lived in another country (more than 3 months)?, (V) Are you currently employed?, while the dependent variable was coded HOME and included the preference of students to remain and follow a further study in the home country. The tree was pruned to avoid overfitting.

The results obtained after applying the CART method are illustrated in Figure 1 and confirm Hypothesis 1.

Therefore, it is shown that the father's level of education influences the students to stay in the country in proportion of $63.5 \%$. Furthermore, $55.6 \%$ of the respondents who stated that their father did not finish high school expressed their intention to leave the country. The majority of students whose father had higher education than high school diploma mentioned they do not want to leave the country (69.6\%). From the results shown it can be concluded that the higher the father's education level, the greater the likelihood of students staying in the country. Moreover, mother's level of education constitutes another influencing factor for students to stay in the country in the same manner as the level of education for the father: if the mother holds a diploma higher than the high school diploma, students are more likely to stay in the country. 
This aspect denotes the fact that students whose parents have a high level of education are more confident about their chances of success in the country and consider that they can benefit from a quality education without leaving abroad.

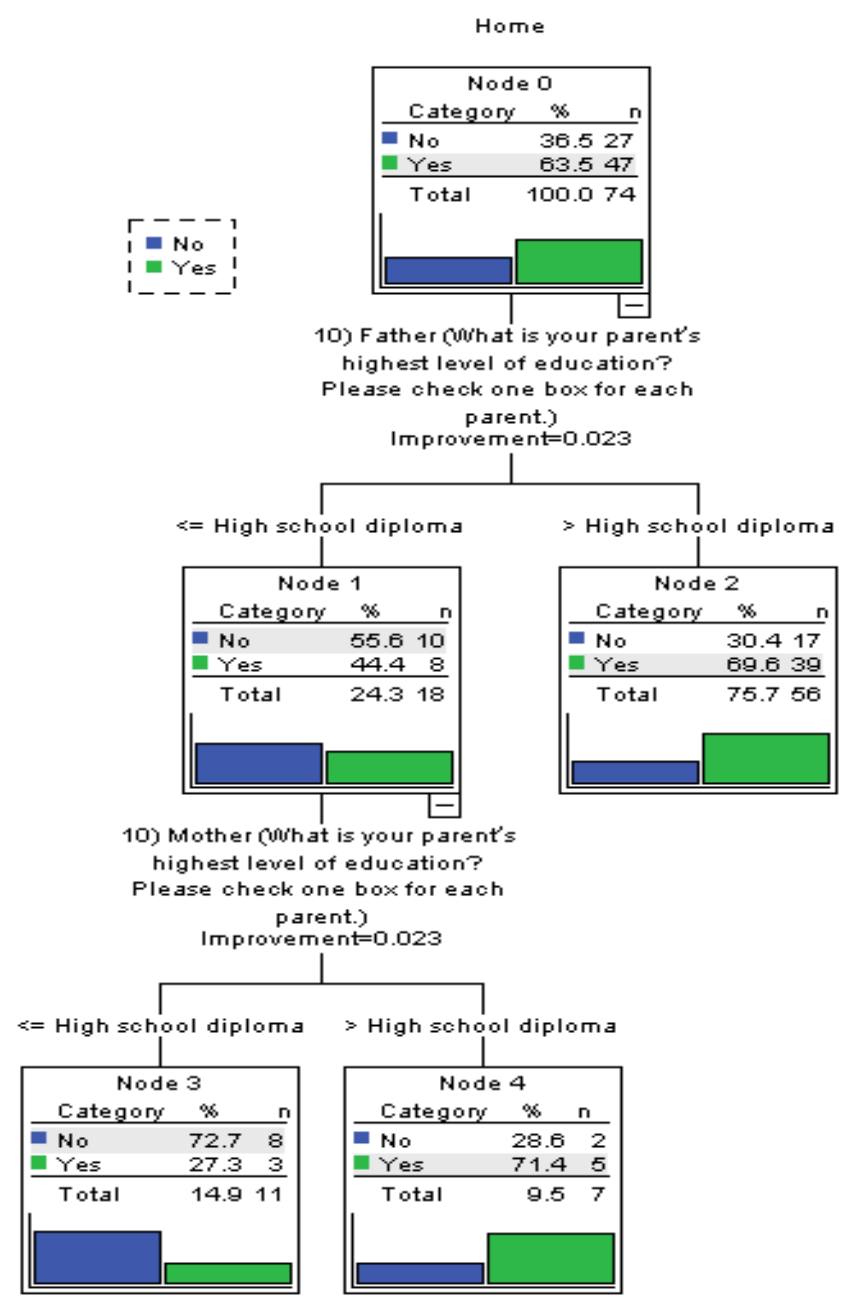

Figure 1. CART analysis of factors influencing students to continue their studies in the home country

Source: Generated by author in SPSS after processing the data

The other variables included in the CART analysis model ("Have you traveled to another country?", "Have you lived in another country (more than 3 months)?", "Are you currently employed?") have no significant influence on students' decision to and continue studying in the country or abroad. The level of importance according to the CART analysis for the five independent variables selected is represented in Figure 2. It is thus found that the level of parent education is the main factor that motivates students to stay or leave the country, 
followed at a great distance by the variable: "Have you lived in another country (more than 3 months)?" Therefore, Hypothesis 2 stating that "Students who have travelled to other countries prefer to study abroad" it is confirmed, but its influence on the students' decision to continue their studies in the country or abroad is not significant for the sample analyzed.

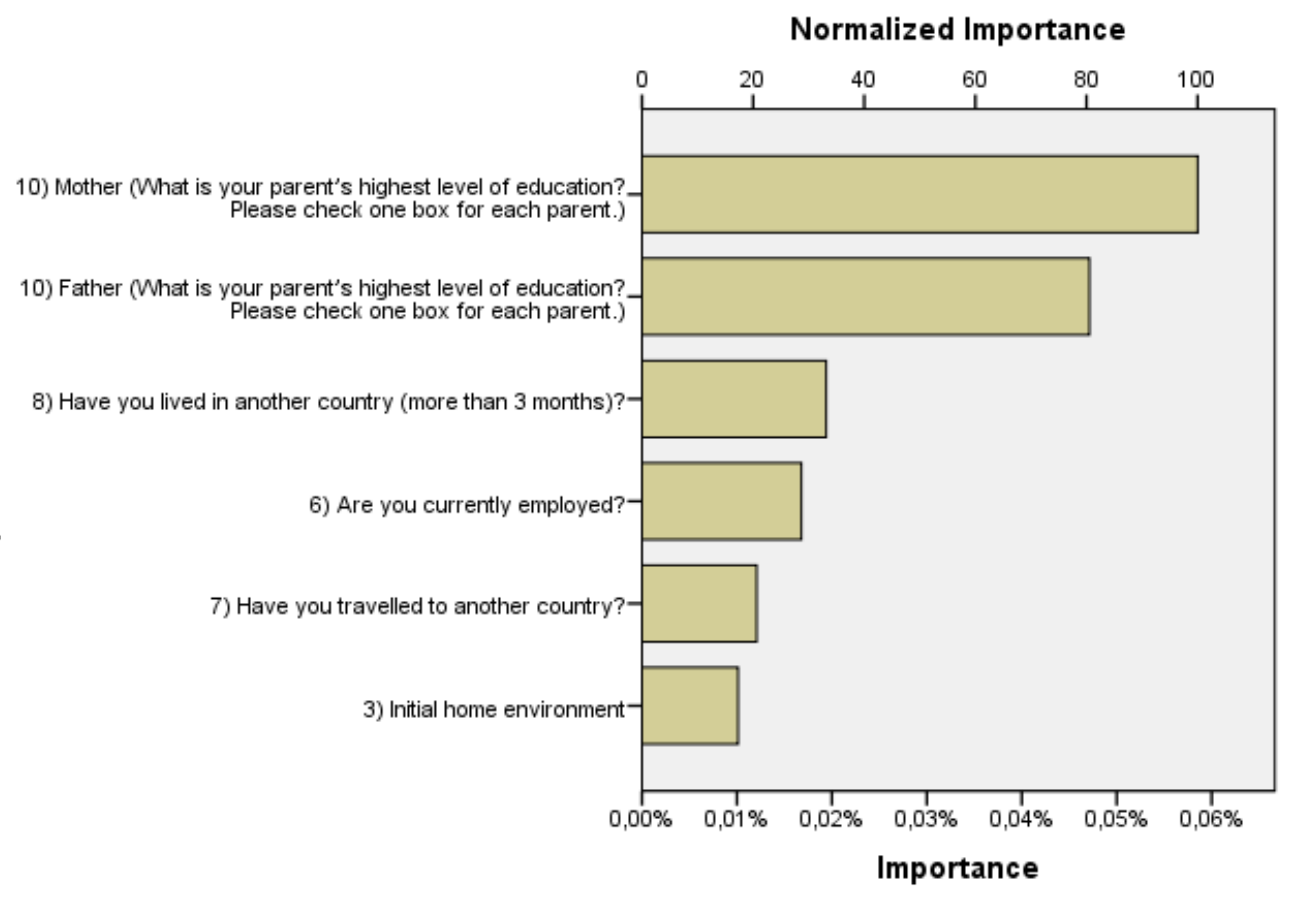

Growing Method:CRT

Dependent Variable:Home

Figure 2. Importance of factors influencing students to continue their studies in the home country

Source: Generated by author in SPSS after processing the data

Hypothesis 3 stated that "The primary reason why students intend to study abroad is to benefit from better quality training". In this regard, the answers to the item "To what extent do you agree or disagree with the following statements? Please check one column for each row. Participating in a study abroad program will help me..." from the questionnaire were analyzed. Only those who had previously expressed their intention to study abroad could select answers for this question. The importance of each answer is shown in Table 1. 
Table 1. Motivators for students to continue their studies abroad

\begin{tabular}{|c|c|c|c|c|c|}
\hline & $\begin{array}{c}\text { Not } \\
\text { Important }\end{array}$ & $\begin{array}{l}\text { Slightly } \\
\text { Important }\end{array}$ & Neutral & Important & $\begin{array}{c}\text { Very } \\
\text { Important }\end{array}$ \\
\hline $\begin{array}{l}\text { Obtain qualifications } \\
\text { recognized by employees }\end{array}$ & $0.0 \%$ & $0.0 \%$ & $0.0 \%$ & $42.9 \%$ & $57.1 \%$ \\
\hline $\begin{array}{l}\text { Obtain a higher income } \\
\text { after graduation }\end{array}$ & $0.0 \%$ & $0.0 \%$ & $14.3 \%$ & $28.6 \%$ & $57.1 \%$ \\
\hline $\begin{array}{l}\text { Have the opportunity to } \\
\text { work during studies }\end{array}$ & $0.0 \%$ & $14.3 \%$ & $14.3 \%$ & $42.9 \%$ & $28.6 \%$ \\
\hline Get better quality education & $14.3 \%$ & $14.3 \%$ & $0.0 \%$ & $0.0 \%$ & $71.4 \%$ \\
\hline $\begin{array}{l}\text { Get accepted easier at the } \\
\text { study program }\end{array}$ & $0.0 \%$ & $0.0 \%$ & $42.9 \%$ & $28.6 \%$ & $28.6 \%$ \\
\hline $\begin{array}{l}\text { Experience different } \\
\text { teaching and learning } \\
\text { methods }\end{array}$ & $14.3 \%$ & $0.0 \%$ & $0.0 \%$ & $42.9 \%$ & $42.9 \%$ \\
\hline $\begin{array}{l}\text { Have access to the latest } \\
\text { information and campus } \\
\text { facilities }\end{array}$ & $0.0 \%$ & $14.3 \%$ & $14.3 \%$ & $14.3 \%$ & $57.1 \%$ \\
\hline $\begin{array}{l}\text { Benefit from better public } \\
\text { infrastructure and amenities }\end{array}$ & $14.3 \%$ & $0.0 \%$ & $28.6 \%$ & $14.3 \%$ & $42.9 \%$ \\
\hline $\begin{array}{l}\text { Learn/improve a foreign } \\
\text { language }\end{array}$ & $0.0 \%$ & $14.3 \%$ & $0.0 \%$ & $42.9 \%$ & $42.9 \%$ \\
\hline $\begin{array}{l}\text { Enhance my understanding } \\
\text { of global affairs and events }\end{array}$ & $14.3 \%$ & $14.3 \%$ & $28.6 \%$ & $14.3 \%$ & $28.6 \%$ \\
\hline $\begin{array}{l}\text { Obtain social prestige of } \\
\text { studying abroad }\end{array}$ & $0.0 \%$ & $0.0 \%$ & $28.6 \%$ & $0.0 \%$ & $71.4 \%$ \\
\hline $\begin{array}{l}\text { Make new friends from } \\
\text { other countries }\end{array}$ & $0.0 \%$ & $14.3 \%$ & $14.3 \%$ & $28.6 \%$ & $42.9 \%$ \\
\hline $\begin{array}{l}\text { Socially/culturally learn } \\
\text { about another culture }\end{array}$ & $14.3 \%$ & $0.0 \%$ & $14.3 \%$ & $28.6 \%$ & $42.9 \%$ \\
\hline $\begin{array}{l}\text { Benefit from a better } \\
\text { climate }\end{array}$ & $14.3 \%$ & $0.0 \%$ & $0.0 \%$ & $57.1 \%$ & $28.6 \%$ \\
\hline To migrate & $14.3 \%$ & $14.3 \%$ & $42.9 \%$ & $14.3 \%$ & $14.3 \%$ \\
\hline Other reasons & $28.6 \%$ & $0.0 \%$ & $42.9 \%$ & $14.3 \%$ & $14.3 \%$ \\
\hline
\end{tabular}

Source: Data synthesized by the author based on the processing of the answers in SPSS

The options considered very important reasons by the students when choosing a course abroad are shaded in the table. It is found that those who wish to continue their studies abroad mainly aim to obtain better quality education $(71.4 \%)$ and to obtain social prestige of studying abroad (71.4\%). These results confirm the previous ones, respectively the students whose parents did not have a high level of education wish to overcome their condition and to obtain a significant social prestige due to the studies undertaken abroad. 


\section{Conclusion}

Upon evaluating the results of the questionnaire using SPSS, it was found that: the main reasons for students deciding to pursue their studies abroad are to obtain better quality education and the social prestige of attending an university outside the country. The father's level of education primarily determines the students to stay in the country in a way that those who stated that their father had not finished high school would like to leave the country. Another major factor that encouraging students to stay or leave the country for further education is their mother's education level, which acts in the same way as the father's education level.

\section{Acknowledgement}

This paper is a result of the research within the 2019-2021 Postdoctoral advanced research program, from The Bucharest University of Economic Studies.

\section{References}

1. Anderson, P. H., \& Lawton, L. (2015). The MSA: An instrument for measuring motivation to study abroad. Frontiers: The Interdisciplinary Journal of Study Abroad

2. Beine, M., Noël, R., \& Ragot, L. (2014). Determinants of the international mobility of students. Economics of Education review, 41, 40-54.

3. Beine, M., Noël, R., \& Ragot, L. (2014). Determinants of the international mobility of students. Economics of Education review, 41, 40-54.

4. Bodycott, P. (2009). Choosing a higher education study abroad destination: What mainland Chinese parents and students rate as important. Journal of research in International education, 8(3), 349-373.

5. Brandenburg, U., \& De Wit, H. (2011). The end of internationalization. International higher education, (62).

6. Docquier, F., \& Rapoport, H. (2012). Globalization, brain drain, and development. Journal of Economic Literature, 50(3), 681-730.

7. Koshy, P., \& Phillimore, J. (2013). Commonwealth Infrastructure Funding for Australian Universities: 2004 to 2011. Australian Universities' Review, 55(2), 99-104.

8. Kratz, F., \& Netz, N. (2018). Which mechanisms explain monetary returns to international student mobility?. Studies in Higher Education, 43(2), 375-400.

9. Lewis, W. (2016). Study Abroad Influencing Factors: An Investigation of Socio-Economic Status, Social, Cultural, and Personal Factors. Ursidae: The Undergraduate Research Journal at the University of Northern Colorado, $5(3), 6$.

10. Luo, J., \& Jamieson-Drake, D. (2015). Predictors of study abroad intent, participation, and college outcomes. Research in Higher Education, 56(1), $29-56$. 
11. Mazzarol, T., \& Soutar, G. N. (2002). "Push-pull" factors influencing international student destination choice. International Journal of Educational Management, 16(2), 82-90.

12. Netz, N. (2015). What deters students from studying abroad? Evidence from four European countries and its implications for higher education policy. Higher Education Policy, 28(2), 151-174.

13. Parey, M., \& Waldinger, F. (2010). Studying abroad and the effect on international labour market mobility: Evidence from the introduction of ERASMUS. The economic journal, 121(551), 194-222.

14. Parey, M., \& Waldinger, F. (2010). Studying abroad and the effect on international labour market mobility: Evidence from the introduction of ERASMUS. The economic journal, 121(551), 194-222.

15. Petzold, K., \& Moog, P. (2018). What shapes the intention to study abroad? An experimental approach. Higher Education, 75(1), 35-54.

16. Petzold, K., \& Peter, T. (2015). The social norm to study abroad: Determinants and effects. Higher education, 69(6), 885-900

17. Schnickel, J., Martin, R., \& Maruyama, Y. (2010) Perspectives on Studying Abroad: Motivations and Challenges. Language, culture, and communication: journal of the College of Intercultural Communication, 2, 103-120.

18. Sidhu, R., Ho, K. C., \& Yeoh, B. S. (2014). Singapore: Building a knowledge and education hub. In International education hubs (pp. 121-143). Springer, Dordrecht.

19. Spilimbergo, A. (2009). Democracy and foreign education. American economic review, 99(1), 528-43.

20. Van Mol, C. (2014). Intra-European student mobility in international higher education circuits: Europe on the move. Springer.

21. Zimmermann, J., \& Neyer, F. J. (2013). Do we become a different person when hitting the road? Personality development of sojourners. Journal of personality and social psychology, 105(3), 515. 